\title{
miR-15b, a diagnostic biomarker and therapeutic target, inhibits oesophageal cancer progression by regulating the PI3K/AKT signalling pathway
}

\author{
JIE LIU $^{1 *}$, HAIYAN XU ${ }^{2 *}$, NAN WANG $^{3}$ and MINGYAN SUN ${ }^{3}$ \\ ${ }^{1}$ Department of Thoracic Surgery, Shandong Institute of Tumor Control, Shandong Cancer Hospital, \\ Shandong First Medical University, Shandong Academy of Medical Sciences, Jinan, Shandong 250000; \\ ${ }^{2}$ The Second Department of Operating Room, Binzhou People's Hospital, Binzhou, Shandong 256610; \\ ${ }^{3}$ Laboratory Department, Affiliated Hospital of Weifang Medical College, Weifang, Shandong 261031, P.R. China
}

Received December 27, 2019; Accepted May 29, 2020

DOI: $10.3892 /$ etm.2020.9352

\begin{abstract}
MicroRNA (miR)-15b is an important regulator in several types of cancer, such as gastric cancer, colorectal cancer and oesophageal squamous cell carcinoma. The PI3K/AKT signalling pathway has been implicated in the growth and metastasis of oesophageal cancer (EC). The aim of the present study was to investigate the biological effects of miR-15b in EC, as well as the underlying mechanism involving the PI3K/AKT signalling pathway. The present study included 74 patients with EC and 74 healthy volunteers. The expression of miR-15b in peripheral blood mononuclear cells (PBMCs) and EC cell lines was evaluated via reverse transcription-quantitative PCR. The receiver operating characteristic curve was plotted to determine the diagnostic significance of miR-15b. EC cell viability, apoptosis, migration and invasion were analysed by conducting MTT, flow cytometry and transwell assays, respectively. Protein expression levels were analysed via western blotting. The results indicated that PBMCs isolated from patients with EC had lower miR-15b expression levels compared with PBMCs isolated from healthy volunteers. In patients with EC, miR-15b expression was strongly associated with tumour size, lymph node metastasis, TNM stage, fibrous membrane invasion and histologic grade. The results of the gain/loss-of-function in vitro experiments indicated that miR-15b inhibited EC cell viability, migration and invasion, facilitated EC cell apoptosis and attenuated the PI3K/AKT signalling pathway in EC109 and TE10 cells. Treatment of EC
\end{abstract}

Correspondence to: Dr Mingyan Sun, Laboratory Department, Affiliated Hospital of Weifang Medical College, 2428 Yuhe Road, Kuiwen, Weifang, Shandong 261031, P.R. China

E-mail: sunmingyan210@163.com

*Contributed equally

Key words: oesophageal cancer, peripheral blood mononuclear cells, microRNA-15b, cell viability, PI3K/AKT signalling pathway cells with the PI3K/AKT pathway agonist recilisib displayed the opposite effects, blocking the inhibitory function of miR-15b mimic on EC cell viability, migration and invasion. In summary, the results indicated that miR-15b suppressed EC cell viability, migration and invasion, and promoted EC cell apoptosis by inhibiting the PI3K/AKT signalling pathway.

\section{Introduction}

Oesophageal cancer (EC) is a common gastrointestinal tumour that can be caused by complex genetic variants or an unhealthy lifestyle (1,2). In 2016, 16,910 new cases of EC and 15,910 deaths caused by EC were recorded in the United States (3). Current treatments for EC, including surgical resection and radiotherapy, have greatly improved the prognosis of patients with EC; however, due to delayed diagnosis and frequent metastasis, the 5-year survival rate (at 41.7\%) remains unsatisfactory (4). Therefore, identifying novel therapeutic targets for EC is crucial to improve clinical outcomes and allow for earlier diagnosis.

MicroRNAs (miRNAs/miRs) are highly conserved, small (18-22 nucleotides) RNA molecules (5). Emerging evidence has demonstrated that miRNAs serve vital roles in various biological processes, such as cell differentiation, viability, apoptosis and the cell cycle, and a number of miRNAs regulate the progression of various types of cancer, such as lung cancer and colon cancer $(6,7)$. The correlation between miRNAs and tumours was first reported in 2002 (8). Several miRNAs, such as miR-206 (9), miR-203a (10) and miR-543 (11), have been reported to be involved in the progression of EC. Previous studies have also demonstrated that miRNAs, which can function as tumour suppressors or cancer-promoting factors, could be useful for predicting cancer prognosis (12-15). The potential of miR-15b has been evaluated in neuroblastoma (12), as well as in colorectal (13) and gastric cancer (14). In addition, Wang et al (15) demonstrated that miR-15b is sponged by long intergenic non-protein coding RNA-regulator of reprogramming, which promotes the development of oesophageal squamous cell carcinoma (ESCC). Based on The Cancer Genome Atlas database, a previous study reported that miR-15b is a novel biomarker for ESCC (16). The results of the 
aforementioned studies suggested that miR-15b may serve as a potential biomarker in EC.

The PI3K/AKT signalling pathway serves an important role in regulating various cellular processes, including cell proliferation, apoptosis, the cell cycle and epithelial-mesenchymal transition (17-19). Increasing evidence suggests that the PI3K/AKT signalling pathway also serves a critical role during the progression of EC $(20,21)$. Sheng et al (20) reported that protease-activated receptor- 2 increases EC cell migration and invasion by activating the PI3K/AKT signalling pathway. In addition, peroxiredoxin 1 knockdown suppresses EC cell proliferation and induces apoptosis by inactivating the PI3K/AKT signalling pathway (21). However, whether the PI3K/AKT signalling pathway is related to the malignant behaviours regulated by miR-15b in EC is not completely understand.

\section{Materials and methods}

Study subjects. In the present study, 74 patients $(<60, \mathrm{n}=30$; $\geq 60, n=44$ ) with EC who had undergone surgery and 74 healthy volunteers $(<60, n=30 ; \geq 60, n=44)$ who had undergone a physical examination between January 2016 and December 2018 were recruited in Shandong Cancer Hospital (Jinan, China). Both patients and healthy volunteer groups comprised of 43 males and 31 females. The age range of the 74 patients was 35 to 66 years. The age range of 74 healthy volunteers matched the age distribution of the patient group. Patients with EC had not been treated with radiotherapy or chemotherapy prior to surgery. Written informed consent was obtained from all participants. The present study was approved by the Ethics Committee of Shandong Cancer Hospital (approval no. 2017024).

Isolation of PBMCs and cell lines. Following a 12-h fast, peripheral blood was collected into EDTA anticoagulant tubes. PBMCs were extracted using Ficoll-Hypaque (450 x g, $20^{\circ} \mathrm{C}$ for $20 \mathrm{~min}$ ), washed by HBSS and resuspended in PBS $\left(1.0 \times 10^{6}\right.$ cells $\left./ \mathrm{ml}\right)$.

Human EC cell lines (EC109 and TE10) were obtained from The Cell Bank of Type Culture Collection of the Chinese Academy of Sciences and cultured in RPMI-1640 medium (Invitrogen; Thermo Fisher Scientific, Inc.) containing 10\% FBS (Invitrogen; Thermo Fisher Scientific, Inc.). HEEpiCs were obtained from ScienCell Research Laboratories, Inc. and cultured in EpiCM2 medium containing 10\% FBS, 5\% EGF and $5 \%$ penicillin/streptomycin (ScienCell Research Laboratories, Inc.). Cells were incubated at $37^{\circ} \mathrm{C}$ in a humidified atmosphere containing $5 \% \mathrm{CO}_{2}$.

Cell transfection. To adjust miR-15b expression levels in EC cells, miR-15b mimics (forward: UAGCAGCACAUCAUG GUUUACA, reverse: UAAACCAUGAUGUGCUGCUAUU), miR-15b inhibitor (forward: UGUAAACCAUGAUGUGCU GCUA), and corresponding mimic negative control (mimics NC, forward: UUCUCCGAACGUGUCACGUTT, reverse: ACGUGACACGUUCGGAGAATT) and inhibitor negative control (inhibitor NC, forward: CAGUACUUUUGUGUA GUACAA) were designed and synthesized by Invitrogen; Thermo Fisher Scientific, Inc.. The non-interference group was used as the blank control. Cells $\left(2 \times 10^{6}\right)$ were transfected with the above agents (miR-15b mimics, mimics NC, miR-15b
Table I. Primers used for reverse transcription-quantitative PCR.

\begin{tabular}{ll}
\hline Gene & \multicolumn{1}{c}{ Sequence $\left(5^{\prime} \rightarrow 3^{\prime}\right)$} \\
\hline MircoRNA-15b & F: TAGCAGCACATCATGGTTTACA \\
& R: TGCGTGTCGTGGAGTC \\
U6 & F: GCTTCGGCAGCACATATACTAAAAT \\
& R: CGCTTCACGAATTTGCGTGTCAT \\
\hline
\end{tabular}

F, forward; R, reverse.

inhibitor and inhibitor $\mathrm{NC} ; 100 \mathrm{nM}$ ) for $48 \mathrm{~h}$ using the Lipofectamine ${ }^{\circledR} 2000$ (Invitrogen; Thermo Fisher Scientific, Inc.) according to the manufacturer's protocol. To determine the association between the PI3K/AKT signalling pathway and miR-15b in EC, transfected EC cells $\left(2 \times 10^{6}\right)$ were cultured in RPMI-1640 medium containing a PI3K/AKT signalling pathway agonist, recilisib $(10 \mu \mathrm{M}$; Sigma-Aldrich; Merck $\mathrm{KGaA})$ at $37^{\circ} \mathrm{C}$ for at least $48 \mathrm{~h}$. The cells were then harvested to perform the following experiments.

$R N A$ extraction and reverse transcription-quantitative $P C R$ $(R T-q P C R)$. After transfection for $24 \mathrm{~h}$, total RNA was extracted from cells using TRIzol ${ }^{\circledR}$ reagent (Invitrogen; Thermo Fisher Scientific, Inc.). The concentration of total RNA was measured using a NanoDrop 2000 spectrophotometer (Thermo Fisher Scientific, Inc.). Total RNA was reverse transcribed into cDNA at $42^{\circ} \mathrm{C}$ for $45 \mathrm{~min}$ using the MiScript Reverse Transcription kit (Qiagen $\mathrm{GmbH}$ ). Subsequently, qPCR was performed using the MiScript SYBR-Green PCR kit (Qiagen GmbH) and an ABI7500 system (Applied Biosystems; Thermo Fisher Scientific, Inc.). The thermocycling conditions were: $94^{\circ} \mathrm{C}$ for $10 \mathrm{~min}$, followed by 40 cycles at $94^{\circ} \mathrm{C}$ for $10 \mathrm{sec}, 60^{\circ} \mathrm{C}$ for $20 \mathrm{sec}$ and $72^{\circ} \mathrm{C}$ for $1 \mathrm{~min}$. The sequences of the primers used in the present study are listed in Table I. Expression levels were quantified using the $2^{-\Delta \Delta \mathrm{Cq}}$ method (22) and normalized to the internal reference gene U6.

Protein isolation and western blotting. At $48 \mathrm{~h}$ post-transfection, total protein was extracted from the cells using RIPA lysis buffer (Beyotime Institute of Biotechnology) and denatured by incubation in $5 \mathrm{X}$ loading buffer (Invitrogen; Thermo Fisher Scientific, Inc.) at $95^{\circ} \mathrm{C}$ for $10 \mathrm{~min}$. BCA Protein Assay kit (Abcam) was used to detect the protein concentrations. Protein (20 $\mu \mathrm{g}$ per lane) was separated via SDS-PAGE (15\%) and transferred to PVDF membranes, which were blocked with $5 \%$ skimmed milk for $2 \mathrm{~h}$ at $25^{\circ} \mathrm{C}$. Subsequently, the membranes were incubated overnight at $4^{\circ} \mathrm{C}$ with primary antibodies targeted against the following: $\mathrm{Bcl}-2$ (1:1,000; cat. no. AF6139; Affinity Biosciences), Bax (1:1,000; cat. no. AF0120; Affinity Biosciences), PI3K (1:1,000; cat. no. AF6241; Affinity Biosciences), phosphorylated (p)-PI3K (1:1,000; cat. no. AF3242; Affinity Biosciences), AKT (1:1,000; cat. no. 4685; Cell Signaling Technology, Inc.) and p-AKT (1:2,000; cat. no. 4060; Cell Signaling Technology, Inc.). After washing three times with TBST (Tween-20; 0.05\%) for $5 \mathrm{~min}$, the membranes were incubated with horseradish 
A

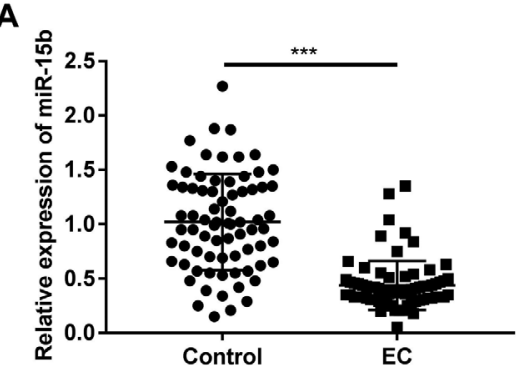

C

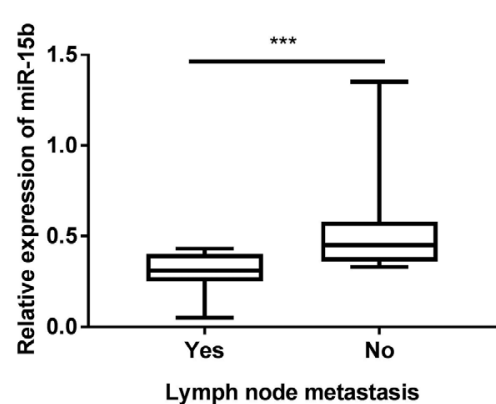

B

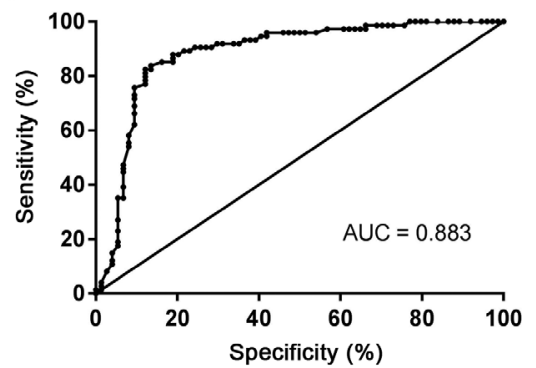

D

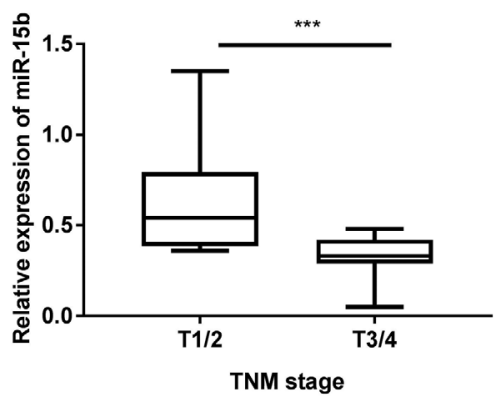

Figure 1. miR-15b is downregulated in PBMCs isolated from patients with EC and serves an important role for the prognosis of EC. (A) Reverse transcription-quantitative PCR was conducted to measure miR-15b expression levels in PBMCs isolated from patients with EC (n=74) and healthy volunteers ( $\mathrm{n}=74)$. (B) The diagnostic value of miR-15b in EC was determined by receiver operating characteristic curve (AUC=0.883). (C) Analysis of miR-15b expression levels in EC tissues with lymph node metastasis. (D) Analysis of miR-15b expression levels and the TNM stage in EC tissues. ${ }^{* * *} \mathrm{P}<0.001$. miR, microRNA; PBMC, peripheral blood mononuclear cells; EC, oesophageal cancer; AUC, area under the curve.

peroxidase-conjugated secondary antibody anti-mice immunoglobulin G (1:5,000; cat. no. 14708; Cell Signaling Technology, Inc.) for $1 \mathrm{~h}$ at $25^{\circ} \mathrm{C}$. GAPDH $(1: 1,000$; cat. no. MA5-15738; Thermo Fisher Scientific, Inc.) was used as the internal reference. The membranes were developed using Chemiluminescence reagents (Thermo Fisher Scientific, Inc.) with a Gel-Pro analyzer (version 4.0; Media Cybernetics, Inc.).

MTT assay. The effect of miR-15b on EC cell viability was assessed by performing the MTT assay. At $24 \mathrm{~h}$ post-transfection, cells were collected and seeded $\left(2 \times 10^{3}\right.$ cells/well $)$ into 96-well plates. At the indicated time point, $20 \mu \mathrm{l}$ MTT reagent ( $5 \mathrm{mg} / \mathrm{ml}$; Sigma-Aldrich; Merck $\mathrm{KGaA}$ ) was added to each well and incubated at $37^{\circ} \mathrm{C}$ with $5 \% \mathrm{CO}_{2}$ for $4 \mathrm{~h}$. DMSO (150 $\mu$; ; Sigma-Aldrich; Merck KGaA) was added to each well and the optical density at $450 \mathrm{~nm}$ was measured using an ELX800 microplate reader (Perkin Elmer, Inc.).

Flow cytometry analysis. The early apoptosis of EC cells was evaluated using the Annexin V-PI apoptosis detection kit (Invitrogen; Thermo Fisher Scientific, Inc.) according to the manufacturer's protocol. Briefly, $1-5 \times 10^{5}$ cells were resuspended in $500 \mu \mathrm{l}$ binding buffer and stained with $5 \mu \mathrm{l}$ Annexin V-EGFP and PI at $4^{\circ} \mathrm{C}$ for $15 \mathrm{~min}$ in the dark. Subsequently, $400 \mu \mathrm{l}$ binding buffer was added to the cells and apoptosis was assessed using a FACScan flow cytometer (version 2.0; Becton, Dickinson and Company).

Transwell invasion and migration assays. Cell invasion was assessed using Transwell chambers (Corning, Inc.) pre-coated (at $37^{\circ} \mathrm{C}$ for $30 \mathrm{~min}$ ) with Matrige ${ }^{\circledR}$ (BD Biosciences). Briefly, transfected EC cells were resuspended in serum-free medium and $200 \mu \mathrm{l}$ cell suspension $\left(1 \times 10^{5}\right.$ cells) was placed in the upper chamber. RPMI-1640 medium containing 10\% FBS $(600 \mu \mathrm{l})$ was added to the lower chamber. Following incubation for $24 \mathrm{~h}$ at $37^{\circ} \mathrm{C}$ with $5 \% \mathrm{CO}_{2}$, cells on the upper surface were removed using a cotton swab. Invading or migratory cells were fixed at room temperature for $20 \mathrm{~min}$ with $3.7 \%$ formaldehyde and stained with $0.1 \%$ crystal violet (at $37^{\circ} \mathrm{C}$ for $15 \mathrm{~min}$ ). Stained cells were observed in five randomly selected fields using a light microscope (magnification, x200). To assess migration, the Transwell chambers were not pre-coated with Matrige ${ }^{\circledR}$ and the cell density in the upper chamber was $3 \times 10^{4}$ cells $/ 200 \mu 1$.

Statistical analysis. Data are presented as the mean \pm SD. Statistical analyses were performed using GraphPad Prism software (version 7.0; GraphPad Software, Inc.). The Student's t-test was used to analyse differences between two groups. One-way ANOVA followed by Tukey's post hoc test was used to analyse differences among multiple groups. The association between miR-15b expression levels and clinical data of patients with EC were analysed using the $\chi^{2}$ test. $\mathrm{P}<0.05$ was considered to indicate a statistically significant difference. The diagnostic analysis was performed through ROC curve analysis with healthy controls as true negative cases and EC patients as true positive cases. Each experiment was performed at least three times.

\section{Results}

miR-15b expression levels are decreased in PBMCs isolated from patients with $E C$. To explore the biological function of miR-15b in EC, RT-qPCR was performed to measure miR-15b expression levels in PBMCs isolated from patients with EC and healthy volunteers. The results indicated that miR-15b expression levels were significantly lower in patients with EC compared with healthy volunteers $(\mathrm{P}<0.001$; Fig. 1A). The 
Table II. Association between microRNA-15b expression and clinical features of patients with oesophageal cancer.

\begin{tabular}{|c|c|c|c|c|}
\hline \multirow[b]{2}{*}{ Variable } & \multirow[b]{2}{*}{ Total } & \multicolumn{2}{|c|}{ MicroRNA-15b expression } & \multirow[b]{2}{*}{ P-value } \\
\hline & & Low & High & \\
\hline Age & & & & 0.344 \\
\hline$<60$ & 30 & 13 & 17 & \\
\hline$\geq 60$ & 44 & 24 & 20 & \\
\hline Gender & & & & 0.48 \\
\hline Male & 43 & 20 & 23 & \\
\hline Female & 31 & 17 & 14 & \\
\hline Tumour size & & & & $0.013^{\mathrm{a}}$ \\
\hline$<2 \mathrm{~cm}$ & 24 & 7 & 17 & \\
\hline$\geq 2 \mathrm{~cm}$ & 50 & 30 & 20 & \\
\hline Lymph node metastasis & & & & $0.034^{\mathrm{a}}$ \\
\hline Yes & 31 & 20 & 11 & \\
\hline No & 43 & 17 & 26 & \\
\hline TNM stage & & & & $0.027^{\mathrm{a}}$ \\
\hline $\mathrm{T} 1 / 2$ & 25 & 8 & 17 & \\
\hline $\mathrm{T} 3 / 4$ & 49 & 29 & 20 & \\
\hline Fibrous membrane invasion & & & & $0.008^{\mathrm{b}}$ \\
\hline Yes & 47 & 29 & 18 & \\
\hline No & 27 & 8 & 19 & \\
\hline Histologic grade & & & & $0.049^{\mathrm{a}}$ \\
\hline Well & 26 & 9 & 17 & \\
\hline Modest & 30 & 15 & 15 & \\
\hline Poor & 18 & 13 & 5 & \\
\hline
\end{tabular}

${ }^{\mathrm{a}} \mathrm{P}<0.05$ and ${ }^{\mathrm{b}} \mathrm{P}<0.01$.

receiver operating characteristic curve revealed that the area under the curve of the EC and control groups distinguished by miR-15b was 0.883 with a cut-off value of $0.525,82.43 \%$ sensitivity and $87.84 \%$ specificity (Fig. 1B). Patients with EC were then divided into two groups (high and low expression) according to the median miR-15b expression level (0.46). The association between miR-15b expression and various clinical parameters was determined and the results are presented in Table II. miR-15b expression was associated with tumour size, lymph node metastasis, TNM stage (23), fibrous membrane invasion and histologic grade $(\mathrm{P}<0.05)$. Moreover, patients with EC with lymph node metastasis displayed significantly lower miR-15b expression levels compared with patients without lymph node metastasis $(\mathrm{P}<0.001$; Fig. $1 \mathrm{C})$. In addition, miR-15b expression levels were significantly lower in patients with T3/4 stage EC compared with patients with T1/2 stage EC $(\mathrm{P}<0.001$; Fig. 1D).

miR-15b reduces EC cell viability and induces apoptosis. To determine the function of $\mathrm{miR}-15 \mathrm{~b}$ in $\mathrm{EC}$, the role of $\mathrm{miR}-15 \mathrm{~b}$ in EC cell viability and apoptosis was assessed. First, miR-15b expression levels in HEEpiC and EC cells (EC109 and TE10) were measured via RT-qPCR. Compared with HEEpiC cells, EC109 and TE10 cells expressed significantly lower levels of
miR-15b ( $\mathrm{P}<0.001$; Fig. 2A). After transfection of miR-15b mimics/NC and miR-15b inhibitor/NC into EC109 and TE10 cells, transfection efficiency was assessed via RT-qPCR. The results indicated that miR-15b mimics significantly increased miR-15b expression in contrast to the mimics NC group, whereas miR-15b inhibitor significantly decreased miR-15b expression in comparison to the inhibitor NC group $(\mathrm{P}<0.01$; Fig. 2B). The overexpression and knockdown cell lines were then used in further experiments to assess the function of miR-15b in EC. The MTT assay results revealed that miR-15b overexpression significantly inhibited EC109 cell viability in contrast to the mimics NC group, whereas miR-15b knockdown significantly enhanced TE10 cell viability in comparison to the inhibitor NC group ( $\mathrm{P}<0.01$; Fig. $2 \mathrm{C})$. Flow cytometry analysis suggested that miR-15b overexpression significantly promoted EC109 cell apoptosis, increased Bax expression and decreased Bcl-2 expression in contrast to the mimics NC group, whereas miR-15b knockdown displayed the opposite effects on TE10 cells ( $\mathrm{P}<0.01$; Fig. 2D and E).

miR $-15 b$ reduces $E C$ cell migration and invasion. Transwell assays were performed to assess the effects of miR-15b on EC cell migration and invasion. miR-15b overexpression significantly decreased EC109 cell migration and invasion $(\mathrm{P}<0.05)$, 
A

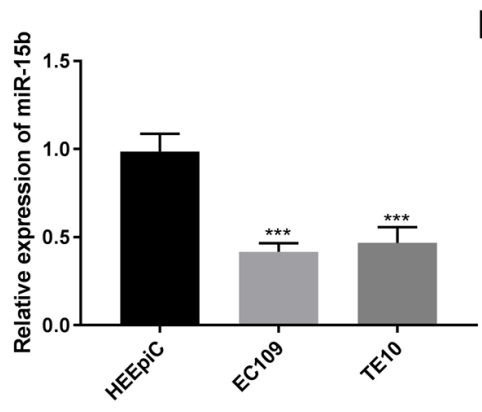

C

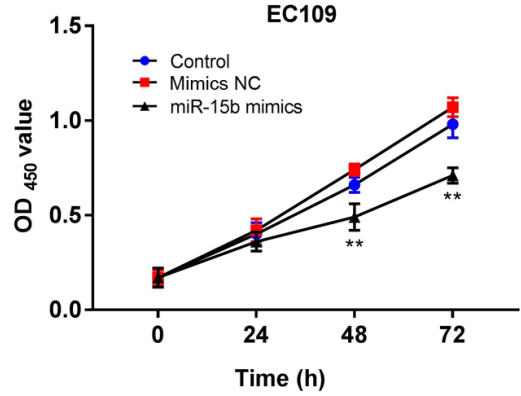

B
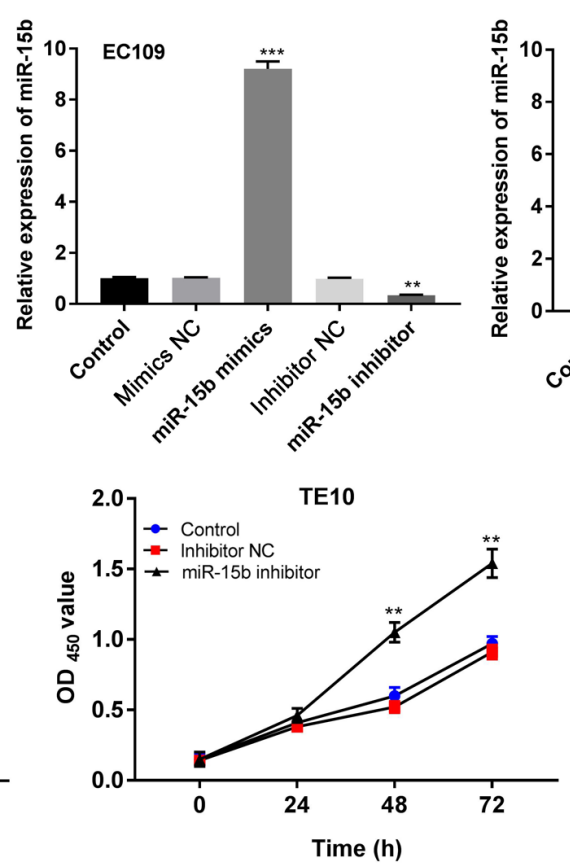

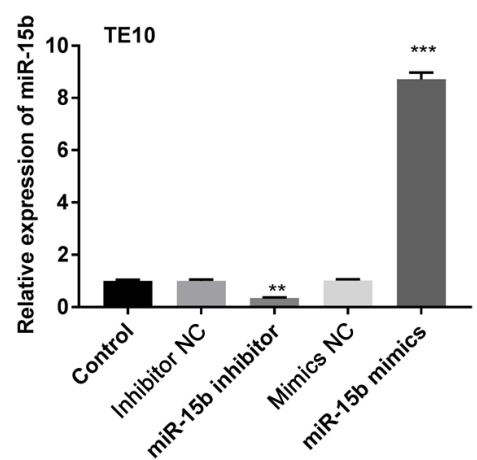

D

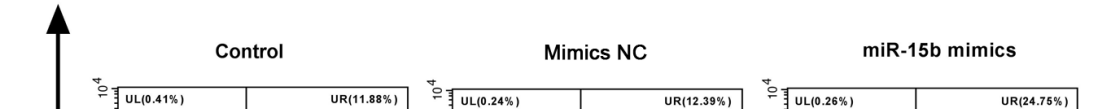

通

$\bar{a}$
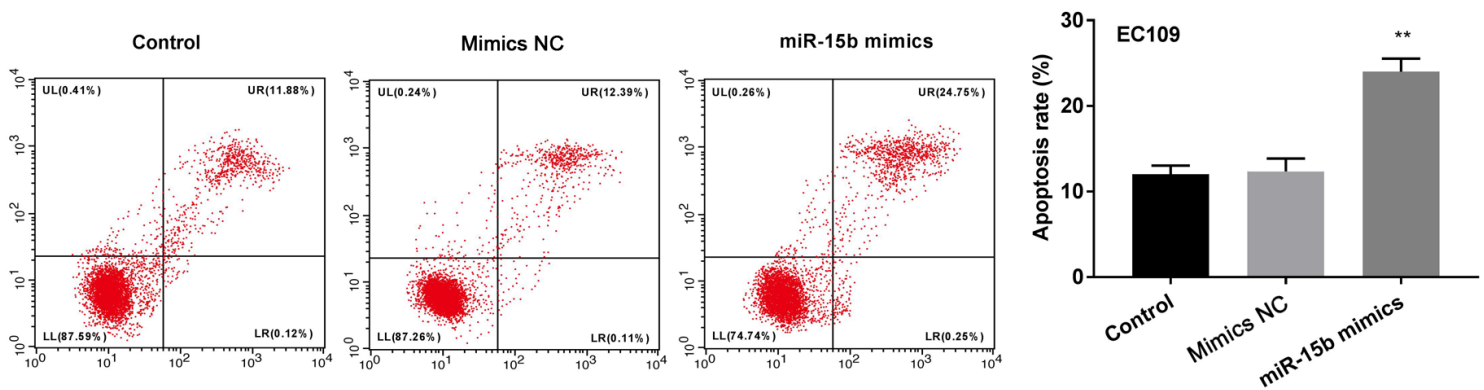

$\stackrel{\circ}{\stackrel{\circ}{H}}$
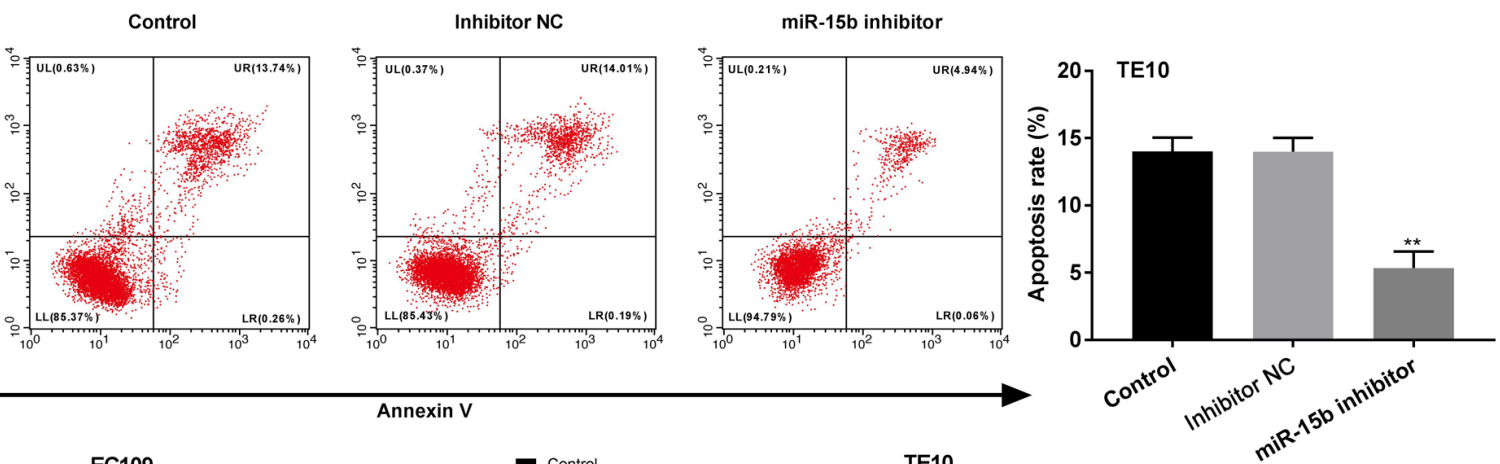

$\mathbf{E}$
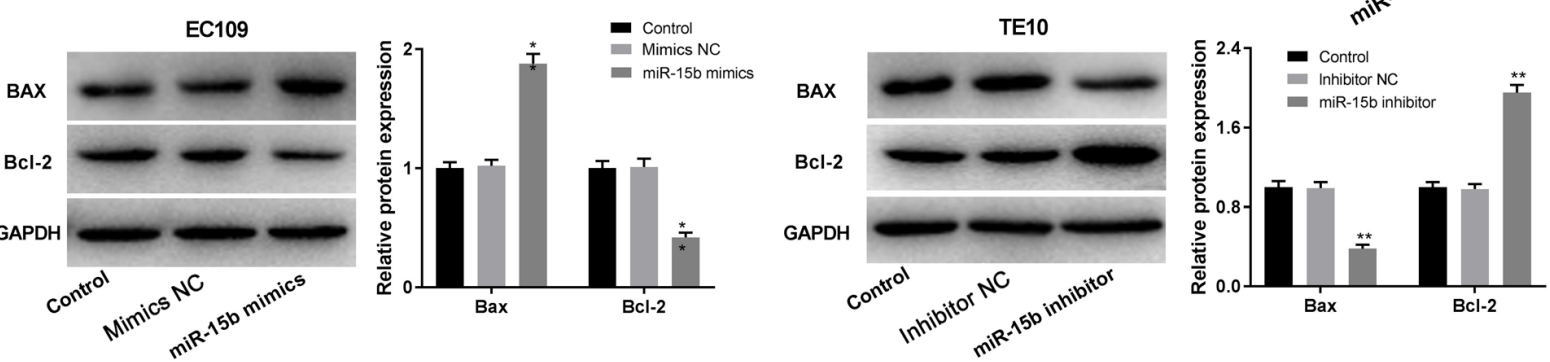

Figure 2. miR-15b reduces EC cell viability and induces apoptosis. (A) miR-15b expression levels in HEEpic, EC109 and TE10 cells. ${ }^{* * *}$ P $<0.001$ vs. HEEpiC (B) Transfection efficiency of miR-15b mimic and miR-15b inhibitor in EC109 and TE10 cells. ${ }^{* *} \mathrm{P}<0.01,{ }^{* * *} \mathrm{P}<0.001$ vs. control. (C) The MTT assay was conducted to assess EC cell viability. (D) EC cell apoptosis was determined by flow cytometry analysis. (E) Relative protein expression levels of Bax and Bcl-2 in EC cells. ${ }^{* *} \mathrm{P}<0.01$ vs. control. miR, microRNA; EC, oesophageal cancer; NC, negative control; OD, optical density; PI, propidium iodide.

whereas miR-15b knockdown significantly increased TE10 cell migration and invasion $(\mathrm{P}<0.01)$ compared with the corresponding NC cells (Fig. 3).
miR-15b inhibits the PI3K/AKT signalling pathway in EC. A previous study demonstrated that miR-15b upregulation suppressed the PI3K/AKT signalling pathway in ovarian 
A
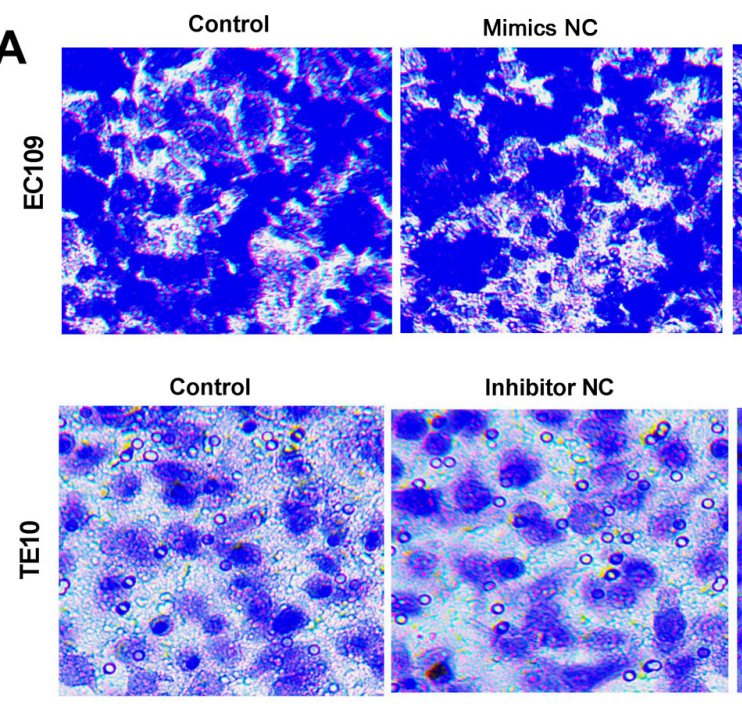

B
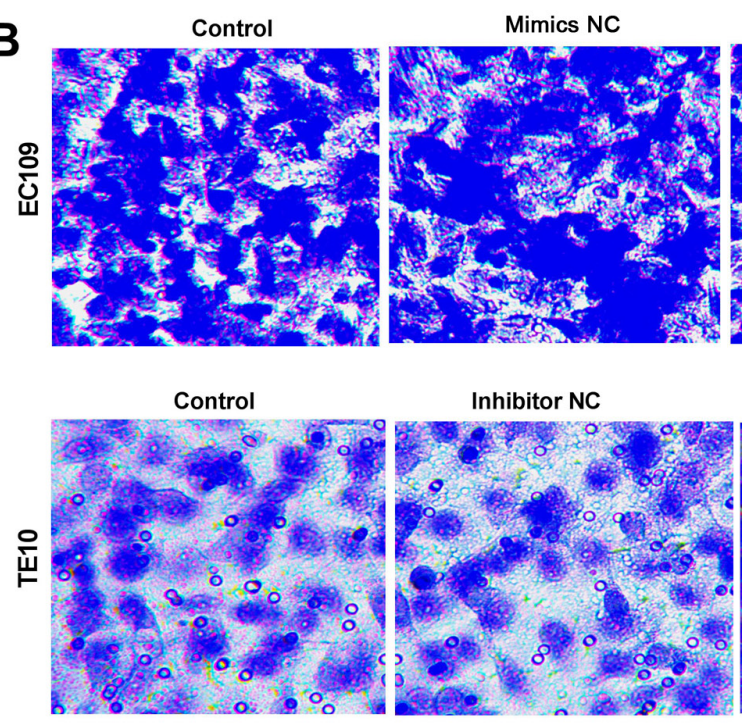

miR-15b mimics

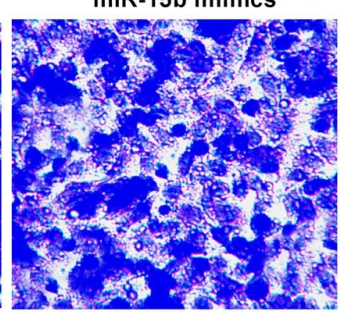

miR-15b inhibitor

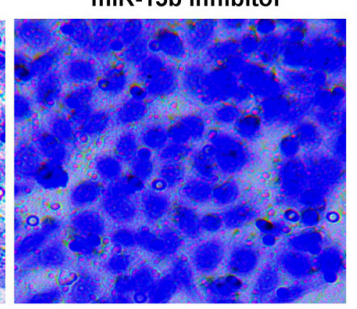

miR-15b mimics

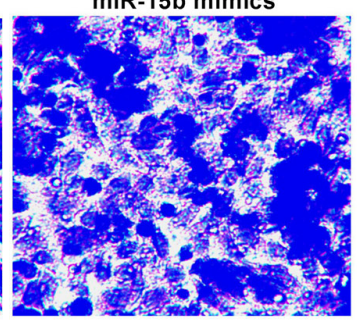

miR-15b inhibitor

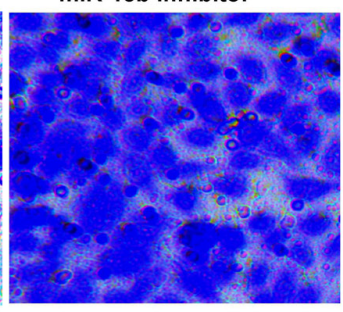

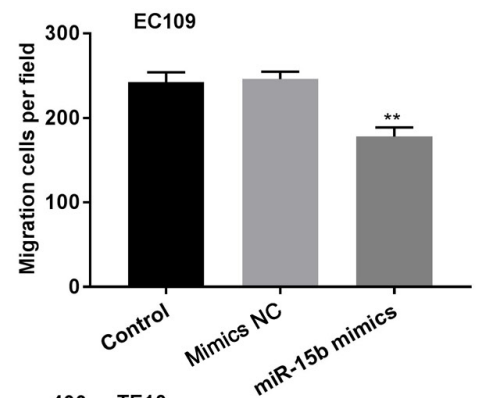
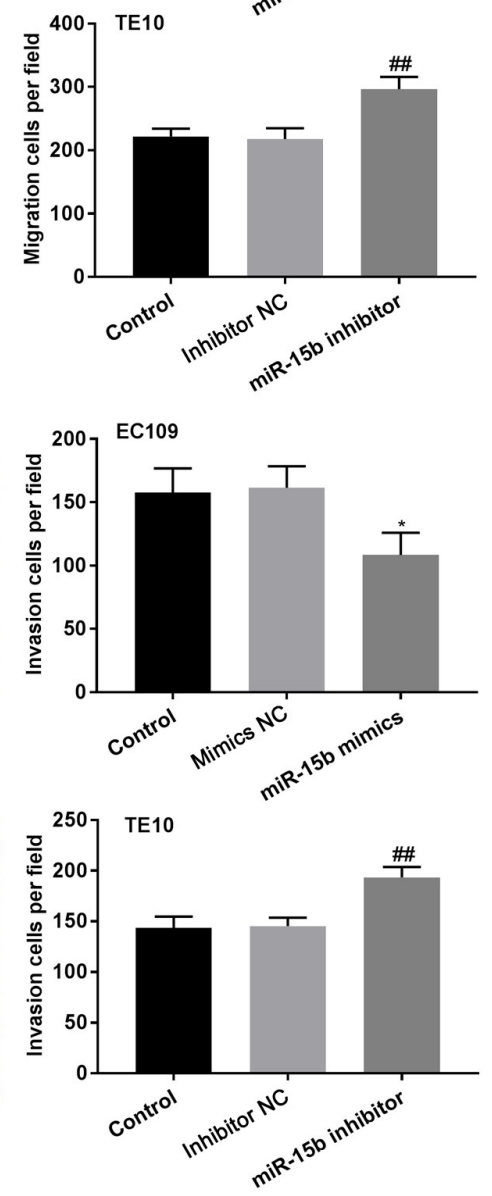

Figure 3. miR-15b attenuates EC cell migration and invasion. Transwell assays were conducted to assess EC109 and TE10 cell (A) migration and (B) invasion. (magnification, $\mathrm{x} 200) .{ }^{*} \mathrm{P}<0.05,{ }^{* *} \mathrm{P}<0.01$ vs. mimics $\mathrm{NC}$; ${ }^{\# \#} \mathrm{P}<0.01$ vs. inhibitor NC. miR, microRNA; NC, negative control.

cancer (23). In addition, activation of the PI3K/AKT signalling pathway increased cancer cell viability and inhibited tumour cell death $(24,25)$. To determine whether the effects of miR-15b in EC were associated with the PI3K/AKT signalling pathway, western blotting was performed. The results indicated that the expression levels of $\mathrm{p}-\mathrm{PI} 3 \mathrm{~K}$ and $\mathrm{p}$-AKT were significantly reduced in miR-15b-overexpression EC109 cells compared to those in the mimics NC EC109 cells, but significantly increased in miR-15b-knockdown TE10 cells compared with the inhibitor NC TE10 cells ( $\mathrm{P}<0.01$; Fig. $4 \mathrm{~A}$ and $\mathrm{B})$. There were no significant differences in the expression levels of PI3K and AKT between miR-15b-overexpression/knockdown cells and the corresponding NC cells ( $\mathrm{P}>0.05$; Fig. 4A and B).

miR-15b suppresses the malignant behaviours of EC cells by regulating the PI3K/AKT signalling pathway. To further explore the relationship between miR-15b and the PI3K/AKT signalling pathway during EC progression, TE10 cells were treated with recilisib, a PI3K/AKT signalling pathway agonist. Recilisib treatment significantly increased the ratios of $\mathrm{p}-\mathrm{PI} 3 \mathrm{~K} / \mathrm{PI} 3 \mathrm{~K}$ and p-AKT/AKT in TE10 cells compared with untreated controls ( $\mathrm{P}<0.01$; Fig. 5A). However, miR-15b mimic significantly reduced recilisib-induced increases in $\mathrm{p}-\mathrm{PI} 3 \mathrm{~K} / \mathrm{PI} 3 \mathrm{~K}$ and $\mathrm{p}-\mathrm{AKT} / \mathrm{AKT}$ ratios in TE10 cells compared with the mimics $\mathrm{NC}+$ recilisib group $(\mathrm{P}<0.01 ;$ Fig. $5 \mathrm{~A})$. Functional in vitro experiments suggested that recilisib significantly promoted TE10 cell viability, migration and invasion, and attenuated TE10 cell apoptosis compared with the control group $(\mathrm{P}<0.01$; Fig. $5 \mathrm{~B}-\mathrm{E})$. However, miR-15b mimic blocked recilisib-induced cell viability, migration and invasion, and also inhibited the inhibitory effects of recilisib on TE10 cell apoptosis ( $\mathrm{P}<0.01$; Fig. 5B-E). Compared with the control group, recilisib treatment significantly decreased Bax expression and increased Bcl-2 expression $(\mathrm{P}<0.01)$, which were reversed by miR-15b mimic $(\mathrm{P}<0.01$; Fig. $5 \mathrm{~F})$. 
A
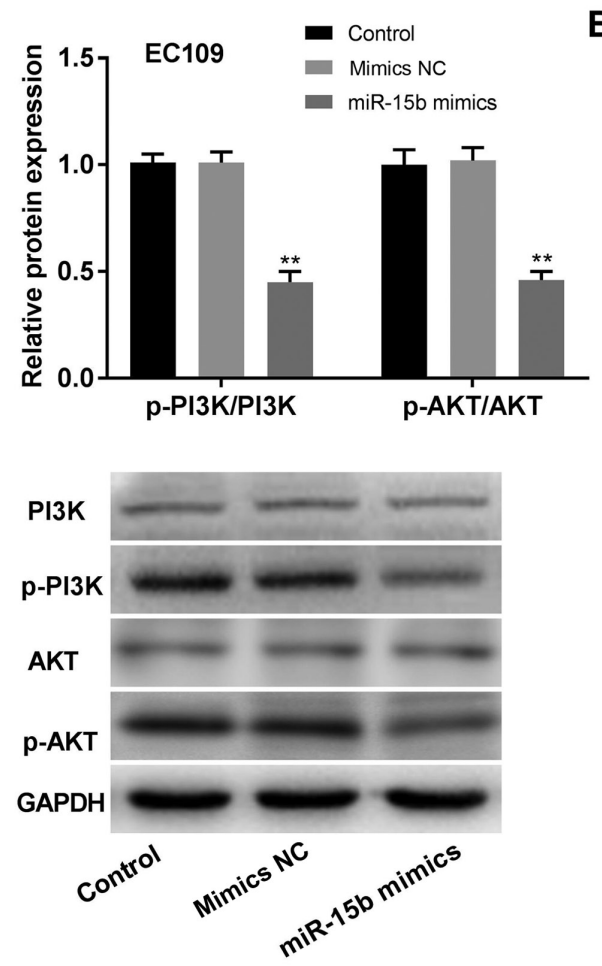

B
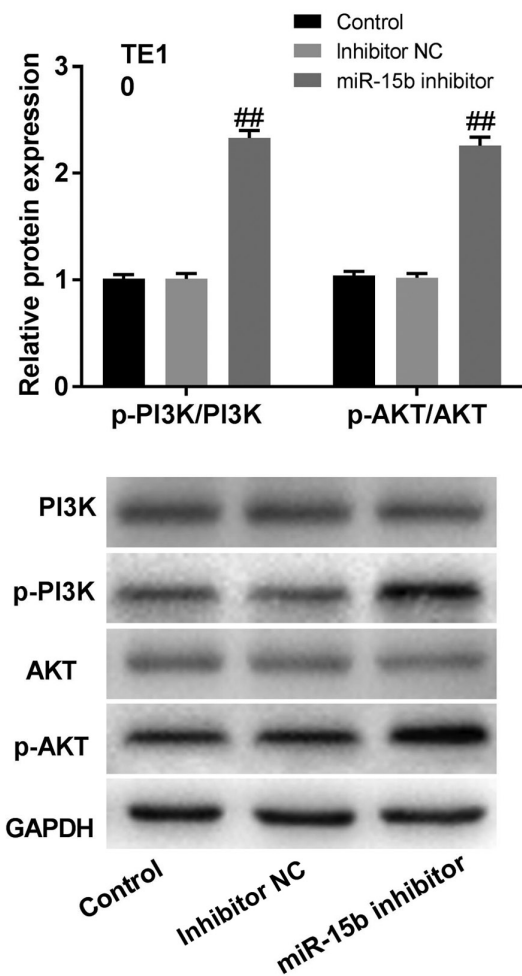

Figure 4. miR-15b impairs the activation of PI3K/AKT signalling pathway in oesophageal cancer. The effect of miR-15b on the PI3K/AKT signalling pathway was investigated via western blotting. p-PI3K/PI3K and p-AKT/AKT ratios in (A) EC109 and (B) TE10 cells. ${ }^{* *} \mathrm{P}<0.01$ vs. mimics NC; ${ }^{\# \#} \mathrm{P}<0.01$ vs. inhibitor NC. miR, microRNA; p, phosphorylated; NC, negative control.

\section{Discussion}

$\mathrm{EC}$ is one of the most serious digestive malignancies, resulting in unfavourable prognosis due to tumour metastasis and recurrence $(24,25)$. The present study suggested that miR-15b expression levels were significantly decreased in PBMCs isolated from patients with EC compared with healthy volunteers. In addition, miR-15b expression was significantly associated with tumour size, lymph node metastasis, TNM stage, fibrous membrane invasion and histologic grade in patients with EC. Li et al (16) identified miR-15b as a potential biomarker for ESCC, and demonstrated that miR-15b was correlated with tumour histological grade, TNM stage and overall survival. miR-15b was also reported to be related to major clinical features in other types of cancer, such as glioblastoma and cervical carcinoma $(26,27)$. The functional in vitro experiments conducted in the present study suggested that miR-15b overexpression inhibited EC cell viability, migration and invasion, and promoted EC cell apoptosis compared with the corresponding NC group. Moreover, the results indicated that the effects of miR-15b were associated with the PI3K/AKT signalling pathway.

miRNAs have received increasing attention as potential therapeutic targets for various tumours, including EC $(9,10,11,28)$. miR-15b is an important RNA molecule that is located on chromosome $3 q 25$ (29). miR-15b levels in PBMCs are correlated with baseline blood glucose concentrations and might serve as a useful indicator of diabetes (30). A previous study demonstrated that miR-15b displays an inhibitory effect on glioblastoma development by inhibiting cell proliferation, cell cycle arrest and invasion (31).
In addition, miR-15b upregulation significantly reduces neuroblastoma cell proliferation, migration and invasion by directly targeting MYCN proto-oncogene, bHLH transcription factor (12). Similarly, miR-15b was reported to function as a tumour suppressor by reducing cellular malignant behaviours in osteosarcoma (32) and oral tongue squamous cell cancer (33). Lu et al (34) demonstrated that miR-15b inhibits thyroid cancer cell proliferation, migration and invasion by regulating Bcl-2. By contrast, miR-15b displays cancer-promoting effects in other types of cancer. For example, miR-15b upregulation improved resistance to sunitinib, and promoted cell survival and invasion in renal cell carcinoma (35). Moreover, miR-15b-5p serves an oncogenic role in hepatocarcinogenesis by mediating multiple complex regulatory pathways (36). Therefore, it was hypothesized that the function of miR-15b may vary according to the type of cancer. In the present study, miR-15b overexpression reduced EC cell viability, invasion and migration, and promoted EC cell apoptosis compared with the corresponding NC group, which suggested that miR-15b might serve a suppressive role in EC.

Accumulating evidence suggests that the PI3K/AKT signalling pathway is associated with the development of EC $(10,37)$. Activation of the PI3K/AKT signalling pathway can increase cancer cell viability and inhibit tumour cell death $(38,39)$. A number of miRNAs are involved in activating the PI3K/AKT signalling pathway. For example, Zheng et al (40) reported that miR-145 could promote apoptosis by suppressing the PI3K/AKT signalling pathway in ESCC. The aggressive phenotype of EC is stimulated by miR-508 via activation of the PI3K/AKT signalling pathway (41). In addition, Pan et al (42) 
A

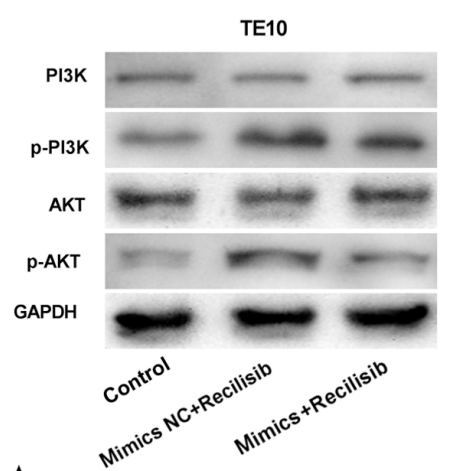

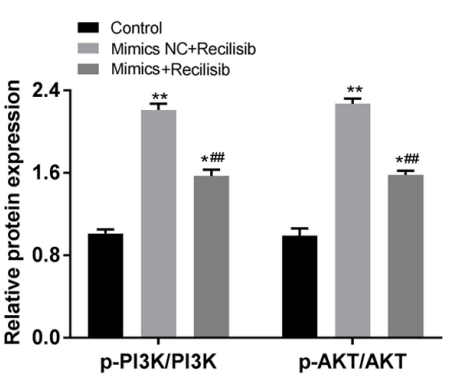

B

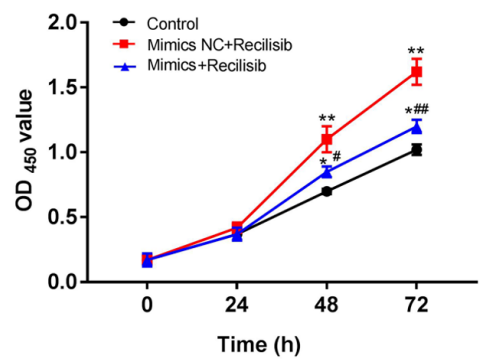

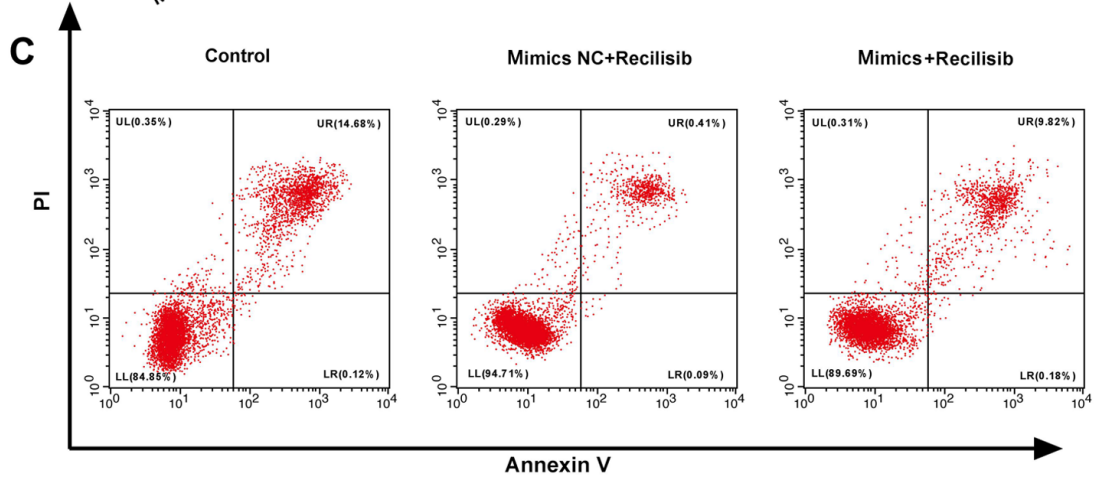

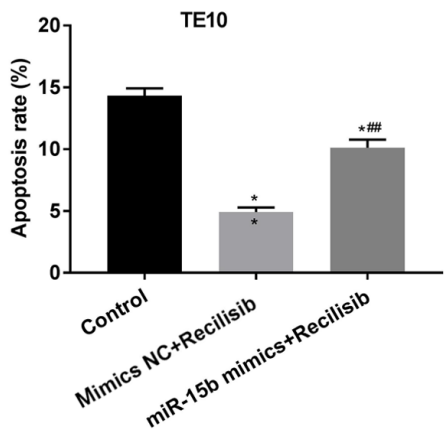

D
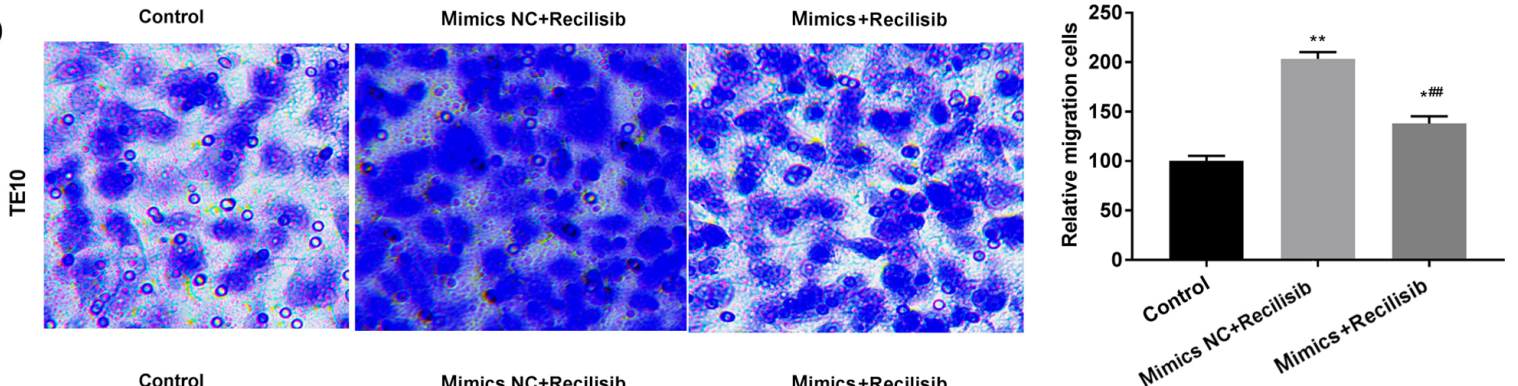

$\mathbf{E}$

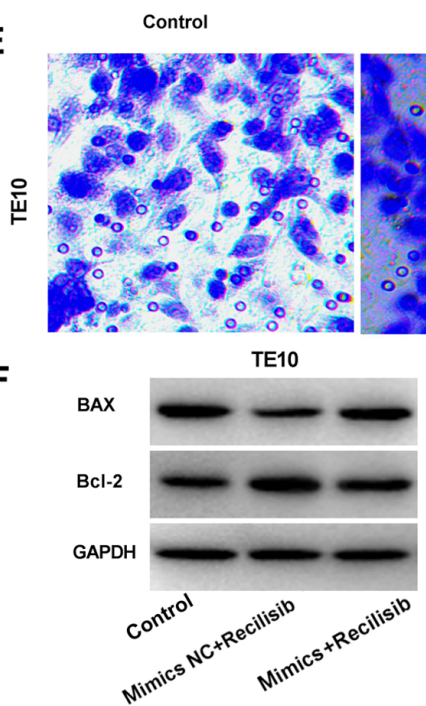

Mimics NC+Recilisib

Mimics+Recilisib
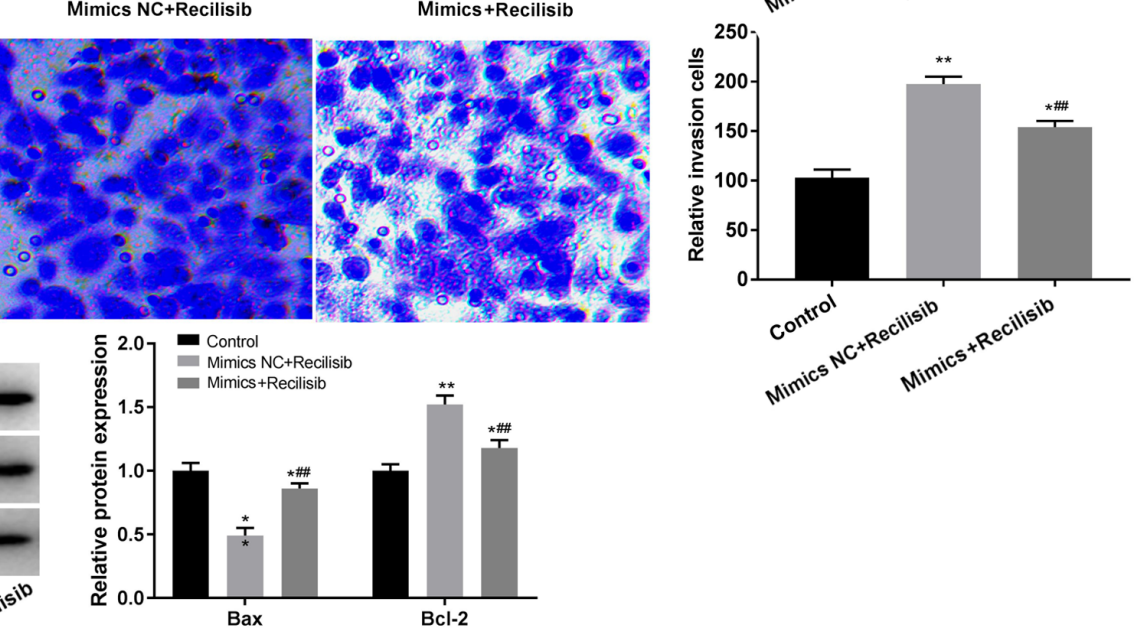

Figure 5. miR-15b suppresses oesophageal cancer cell malignant behaviours by mediating the PI3K/AKT signalling pathway. (A) Western blotting was performed to measure the expression levels of PI3K/AKT signalling pathway-related proteins. TE10 cell. (B) viability, (C) apoptosis, (D) migration and (E) invasion (magnification, x200) were detected by performing MTT, flow cytometry and Transwell assays, respectively. (F) Western blotting was performed to measure the expression levels of Bax and Bcl-2 in TE10 cells. ${ }^{*} \mathrm{P}<0.05,{ }^{* *} \mathrm{P}<0.01$ vs. control; ${ }^{\# \#} \mathrm{P}<0.01$ vs. mimics $\mathrm{NC}+\mathrm{Recilisib}$. miR, microRNA; p, phosphorylated; NC, negative control; OD, optical density; PI, propidium iodide.

demonstrated that miR-205 can promote radioresistance by regulating the PI3K/AKT signalling pathway in ESCC, which affects clinical outcomes. miR-15b overexpression alleviated ovarian cancer by inhibiting the PI3K/AKT signalling pathway (43). By contrast, miR-15b participates in the development of peripheral arterial disease by inactivating the PI3K/AKT signalling pathway (44). Therefore, it was speculated that the effects of miR-15b in EC may be related 
to the PI3K/AKT signalling pathway. Mechanistically, AKT and PI3K serve vital roles in PI3K/AKT/mTOR signalling (45) as PI3K binds stably to the pleckstrin homology domain of AKT, partially activating it (46). The results of the present study suggested that miR-15b may block activation of the PI3K/AKT signalling pathway in EC cells by reducing p-PI3K and p-AKT expression levels. Some compounds, such as PI3K activators or inhibitors, have been widely used to explore the crosstalk between the PI3K/AKT signalling pathway and various miRNAs in tumorigenesis $(47,48)$. The PI3K/AKT pathway activator recilisib was used in the present study, and the results indicated that recilisib increased cell viability, migration and invasion, and promoted apoptosis in TE10 cells. In addition, recilisib reversed the inhibitory effects of miR-15b overexpression.

In conclusion, in the present study, miR-15b expression levels were significantly lower in PBMCs isolated from patients with EC compared with PBMCs isolated from healthy controls. In addition, miR-15b expression was associated with various clinicopathological characteristics in patients with EC. Functional in vitro experiments further indicated that miR-15b may function as a suppressive factor in EC by inhibiting the PI3K/AKT signalling pathway. In summary, the present study improved the current understanding of the mechanism underlying EC and suggested potential novel therapeutic targets for EC.

\section{Acknowledgements}

Not applicable.

\section{Funding}

No funding was received.

\section{Availability of data and materials}

The datasets used and/or analysed during the current study are available from the corresponding author on reasonable request.

\section{Authors' contributions}

JL made substantial contributions to the conception and design of the study. JL, HX, NW and MS made substantial contributions to the acquisition, analysis and interpretation of data, as well as the drafting and revision of the manuscript. All authors agreed to be accountable for the work, read and approved the final version of the manuscript.

\section{Ethics approval and consent to participate}

Written informed consent was obtained from all participants. The present study was approved by the Ethics Committee of Shandong Cancer Hospital (Jinan, China; approval no. 2017024).

\section{Patient consent for publication}

Not applicable.

\section{Competing interests}

The authors declare that they have no competing interests.

\section{References}

1. Jia X, Liu P, Zhang M, Feng T, Tang H, Tang Z, Zhao H and Jin T: Genetic variants at $6 \mathrm{p} 21,10 \mathrm{q} 23,16 \mathrm{q} 21$ and 22q12 are associated with esophageal cancer risk in a Chinese Han population. Int J Clin Exp Med 8: 19381-19387, 2015.

2. Oze I, Matsuo K, Wakai K, Nagata C, Mizoue T, Tanaka K, Tsuji I, Sasazuki S, Inoue M and Tsugane S; Research Group for the Development and Evaluation of Cancer Prevention Strategies in Japan: Alcohol drinking and esophageal cancer risk: An evaluation based on a systematic review of epidemiologic evidence among the Japanese population. Jpn J Clin Oncol 41: 677-692, 2011.

3. Short MW, Burgers KG and Fry VT: Esophageal cancer. Am Fam Physician 95: 22-28, 2017.

4. Yang C, Shen S, Zheng X, Ye K, Sun Y, Lu Y and Ge H: Long noncoding RNA HAGLR acts as a microRNA-143-5p sponge to regulate epithelial-mesenchymal transition and metastatic potential in esophageal cancer by regulating LAMP3. FASEB J 33: 10490-10504, 2019.

5. Lowery AJ, Miller N, McNeill RE and Kerin MJ: MicroRNAs as prognostic indicators and therapeutic targets: Potential effect on breast cancer management. Clin Cancer Res 14: 360-365, 2008.

6. Guo L and Lu Z: The fate of miRNA* strand through evolutionary analysis: Implication for degradation as merely carrier strand or potential regulatory molecule? PLoS One 5: e11387, 2010.

7. He L and Hannon GJ: MicroRNAs: Small RNAs with a big role in gene regulation. Nat Rev Genet 5: 522-531, 2004.

8. Calin GA, Dumitru CD, Shimizu M, Bichi R, Zupo S, Noch E, Aldler H, Rattan S, Keating M, Rai K, et al: Frequent deletions and down-regulation of micro-RNA genes miR15 and miR16 at $13 q 14$ in chronic lymphocytic leukemia. Proc Natl Acad Sci USA 99: 15524-15529, 2002.

9. Du G, Zhou J, Cheng L, Ma X, Gui Y and Tan B: High expression of miR-206 predicts adverse outcomes: A potential therapeutic target for esophageal cancer. Comb Chem High Throughput Screen 22: 599-611, 2019.

10. Wang L, Zhang Z, Yu X, Li Q, Wang Q, Chang A, Huang X, Han X, Song Y, Hu J, et al: SOX9/miR-203a axis drives $\mathrm{PI} 3 \mathrm{~K} / \mathrm{AKT}$ signaling to promote esophageal cancer progression. Cancer Lett 468: 14-26, 2020.

11. Zhang L, Chen J, Wang L, Chen L, Du Z, Zhu L, Cui M, Zhang $\mathrm{M}$ and Song L: Linc-PINT acted as a tumor suppressor by sponging miR-543 and miR-576-5p in esophageal cancer. J Cell Biochem 120: 19345-19357, 2019.

12. Chava S, Reynolds CP, Pathania AS, Gorantla S, Poluektova LY, Coulter DW, Gupta SC, Pandey MK and Challagundla KB: MiR-15a-5p, miR-15b-5p, and miR-16-5p inhibit tumor progression by directly targeting MYCN in neuroblastoma. Mol Oncol 14: 180-196, 2020 .

13. Marcuello M, Duran-Sanchon S, Moreno L, Lozano JJ, Bujanda L, Castells A and Gironella M: Analysis of A 6-Mirna signature in serum from colorectal cancer screening participants as non-invasive biomarkers for advanced adenoma and colorectal cancer detection. Cancers (Basel) 11: 1542, 2019.

14. Yuan $\mathrm{C}$, Zhang Y, Tu W and Guo Y: Integrated miRNA profiling and bioinformatics analyses reveal upregulated miRNAs in gastric cancer. Oncol Lett 18: 1979-1988, 2019.

15. Wang L, Yu X, Zhang Z, Pang L, Xu J, Jiang J, Liang W, Chai Y, Hou J and Li F: Linc-ROR promotes esophageal squamous cell carcinoma progression through the derepression of SOX9. J Exp Clin Cancer Res 36: 182, 2017.

16. Li CY, Zhang WW, Xiang JL, Wang XH, Li J and Wang JL: Identification of microRNAs as novel biomarkers for esophageal squamous cell carcinoma: A study based on the cancer genome atlas (TCGA) and bioinformatics. Chin Med J (Engl) 132: 2213-2222, 2019.

17. Liu Z, Chen M, Xie LK, Liu T, Zou ZW, Li Y, Chen P, Peng X, Ma C, Zhang WJ and Li PD: CLCA4 inhibits cell proliferation and invasion of hepatocellular carcinoma by suppressing epithelial-mesenchymal transition via PI3K/AKT signaling. Aging (Albany NY) 10: 2570-2584, 2018. 
18. Yang J, Zhang L, Jiang Z, Ge C, Zhao F, Jiang J, Tian H, Chen T, $\mathrm{Xie} \mathrm{H}$, Cui Y, et al: TCF12 promotes the tumorigenesis and metastasis of hepatocellular carcinoma via upregulation of CXCR4 expression. Theranostics 9: 5810-5827, 2019.

19. Zhang F, Li K, Yao X, Wang H, Li W, Wu J, Li M, Zhou R, Xu L and Zhao L: A miR-567-PIK3AP1-PI3K/AKT-c-Myc feedback loop regulates tumour growth and chemoresistance in gastric cancer. EBioMedicine 44: 311-321, 2019.

20. Sheng J, Deng X, Zhang Q, Liu H, Wang N, Liu Z, Dai E and Deng Q: PAR-2 promotes invasion and migration of esophageal cancer cells by activating MEK/ERK and PI3K/Akt signaling pathway. Int J Clin Exp Pathol 12: 787-797, 2019.

21. Song Y, Liu H, Cui C, Peng X, Wang C, Tian X and Li W: Silencing of peroxiredoxin 1 inhibits the proliferation of esophageal cancer cells and promotes apoptosis by inhibiting the activity of the PI3K/AKT pathway. Cancer Manag Res 11: 10883-10890, 2019.

22. Livak KJ and Schmittgen TD: Analysis of relative gene expression data using real-time quantitative PCR and the 2(-Delta Delta C(T)) method. Methods 25: 402-408, 2001.

23. Zhang J, Zhou Y, Jiang K, Shen Z, Ye Y and Wang S: Evaluation of the seventh AJCC TNM staging system for gastric cancer: A meta-analysis of cohort studies. Tumour Biol 35: 8525-8532, 2014

24. Shimada A, Tsushima T, Tsubosa Y, Booka E, Takebayashi K, Niihara M, Isaka M, Ohde Y, Machida N, Onozawa Y, et al: Validity of surgical resection for lymph node or pulmonary recurrence of esophageal cancer after definitive treatment. World J Surg 43: 1286-1293, 2019.

25. Steffen T, Dietrich D, Schnider A, Kettelhack C, Huber O, Marti WR, Furrer M, Gloor B, Schiesser M, Thierstein S, et al: Recurrence patterns and long-term results after induction chemotherapy, chemoradiotherapy, and curative surgery in patients with locally advanced esophageal cancer. Ann Surg 269: 83-87, 2019.

26. Matos B, Bostjancic E, Matjasic A, Popovic M and Glavac D: Dynamic expression of 11 miRNAs in 83 consecutive primary and corresponding recurrent glioblastoma: Correlation to treatment, time to recurrence, overall survival and MGMT methylation status. Radiol Oncol 52: 422-432, 2018.

27. Wen F, Xu JZ and Wang XR: Increased expression of miR-15b is associated with clinicopathological features and poor prognosis in cervical carcinoma. Arch Gynecol Obstet 295: 743-749, 2017.

28. Liu Z, Hu G, Zhao Y, Xiao Z, Yan M and Ren M: Silence of cZNF292 suppresses the growth, migration, and invasion of human esophageal cancer Eca-109 cells via upregulating miR-206. J Cell Biochem 121: 2354-2362, 2020

29. Lovat F, Fassan M, Sacchi D, Ranganathan P, Palamarchuk A, Bill M, Karunasiri M, Gasparini P, Nigita G, Distefano R, et al: Knockout of both miR-15/16 loci induces acute myeloid leukemia. Proc Natl Acad Sci USA 115: 13069-13074, 2018.

30. Gottmann P, Ouni M, Saussenthaler S, Roos J, Stirm L, Jähnert M, Kamitz A, Hallahan N, Jonas W, Fritsche A, et al: A computational biology approach of a genome-wide screen connected miRNAs to obesity and type 2 diabetes. Mol Metab 11: 145-159, 2018.

31. Wang J, Liu H, Tian L, Wang F, Han L, Zhang W and Bai YA MiR-15b inhibits the progression of glioblastoma cells through targeting insulin-like growth factor receptor 1 . Horm Cancer 8: 49-57, 2017

32. Weng Y, Shen Y, He Y, Pan X, Xu J, Jiang Y, Zhang Q, Wang S, Kong $\mathrm{F}$, Zhao $\mathrm{S}$, et al: The miR-15b-5p/PDK4 axis regulates osteosarcoma proliferation through modulation of the Warburg effect. Biochem Biophys Res Commun 503: 2749-2757, 2018.
33. Xin QL, Deng CL, Chen X, Wang J, Wang SB, Wang W, Deng F, Zhang B, Xiao G and Zhang LK: Quantitative proteomic analysis of mosquito $\mathrm{C} 6 / 36$ cells reveals host proteins involved in Zika virus infection. J Virol 91: e00554-17, 2017.

34. Lu Z, Wu Z, Hu J, Wei W, Ma B and Wen D: MicroRNA-15 regulates the proliferation, migration and invasion of thyroid cancer cells by targeting Bcl-2. J BUON 24: 2114-2119, 2019.

35. Lu L, Li Y, Wen H and Feng C: Overexpression of miR-15b promotes resistance to sunitinib in renal cell carcinoma. J Cancer 10: 3389-3396, 2019.

36. Pan WY, Zeng JH, Wen DY, Wang JY, Wang PP, Chen G and Feng ZB: Oncogenic value of microRNA-15b-5p in hepatocellular carcinoma and a bioinformatics investigation. Oncol Lett 17: 1695-1713, 2019.

37. Shi N, Yu H and Chen T: Inhibition of esophageal cancer growth through the suppression of PI3K/AKT/mTOR signaling pathway. Onco Targets Ther 12: 7637-7647, 2019.

38. Yang SX, Polley E and Lipkowitz S: New insights on PI3K/AKT pathway alterations and clinical outcomes in breast cancer. Cancer Treat Rev 45: 87-96, 2016.

39. Janku F, Yap TA and Meric-Bernstam F: Targeting the PI3K pathway in cancer: Are we making headway? Nat Rev Clin Oncol 15: 273-291, 2018.

40. Zheng TL, Li DP, He ZF and Zhao S: miR-145 sensitizes esophageal squamous cell carcinoma to cisplatin through directly inhibiting PI3K/AKT signaling pathway. Cancer Cell Int 19: 250, 2019.

41. Lin C, Liu A, Zhu J, Zhang X, Wu G, Ren P, Wu J, Li M, Li J and Song L: miR-508 sustains phosphoinositide signalling and promotes aggressive phenotype of oesophageal squamous cell carcinoma. Nat Commun 5: 4620, 2014.

42. Pan F, Mao H, Bu F, Tong X, Li J, Zhang S, Liu X, Wang L, Wu L, Chen R, et al: Spl-mediated transcriptional activation of miR-205 promotes radioresistance in esophageal squamous cell carcinoma. Oncotarget 8: 5735-5752, 2017.

43. Li GC, Qin XL, Song HH, Li YN, Qiu YY, Cui SC, Wang YS, Wang $\mathrm{H}$ and Gong JL: Upregulated microRNA-15b alleviates ovarian cancer through inhitbition of the PI3K/Akt pathway by targeting LPAR3. J Cell Physiol 234: 22331-22342, 2019.

44. Sun Y, Gao Y, Song T, Yu C, Nie Z and Wang X: MicroRNA-15b participates in the development of peripheral arterial disease by modulating the growth of vascular smooth muscle cells. Exp Ther Med 18: 77-84, 2019.

45. Park J, Feng J,Li Y, Hammarsten O, Brazil DP and Hemmings BA: DNA-dependent protein kinase-mediated phosphorylation of protein kinase $\mathrm{B}$ requires a specific recognition sequence in the C-terminal hydrophobic motif. J Biol Chem 284: 6169-6174, 2009.

46. Szymonowicz K, Oeck S, Malewicz NM and Jendrossek V: New insights into protein kinase B/Akt signaling: Role of localized Akt activation and compartment-specific target proteins for the cellular radiation response. Cancers (Basel) 10: 78, 2018.

47. Porta C, Paglino C and Mosca A: Targeting PI3K/Akt/mTOR Signaling in cancer. Front Oncol 4: 64, 2014.

48. Hu H, Wang F, Wang M, Liu Y, Wu H, Chen X and Lin Q FAM83A is amplified and promotes tumorigenicity in non-small cell lung cancer via ERK and PI3K/Akt/mTOR pathways. Int J Med Sci 17: 807-814, 2020. 